\title{
The Simulation and Prototyping of a Density-Based Smart Traffic Control System for Learning Purposes
}

\author{
https://doi.org/10.3991/ijoe.v16i12.16849
}

\author{
Mashael Khayyat ${ }^{(凶)}$, Omar Abouola, Nahla aljojo, Basma Alharbi, \\ Nada Almalki, Maysoon Al-zahrani, Tasneem Al-ghamdi, Lama Al-qarni \\ University of Jeddah, Jeddah, Saudi Arabia \\ mkhayyat@uj.edu.sa
}

\begin{abstract}
With the tremendous technological progress and the widespread use of a variety of technologies, we note how smart cities are providing services efficiently by using technologies. The aim of this project is to build a Smart Traffic Control System (STCS) to facilitate and optimize traffic flow, minimize traffic congestion, and reduce the waiting time by detecting the density on each street. This work has been carried on four phases. Firstly, collecting data by a questionnaire and we received 331 responses. Secondly, using Proteus simulation. Thirdly, building a low fidelity prototype, and fourthly: building the STCS model by using hardware (Arduino tools) and software (Arduino Software IDE). Finally, we learned how to build a system and we recommend using such a system in busy roads to reduced congestion and making traffic flow more efficient.
\end{abstract}

Keywords - Traffic congestion, traffic lights monitoring, IoT, Arduino, Road Sensors, Proteus simulation.

\section{Introduction}

Recently, technology represents an integral part of our life and it is impractical to imagine our life without embedded devices [1]. Technology changes the lifestyle to be more efficient and reliable [2]. The scientific development witnessed by the modern world in the technological industries, which took the form of innovation and ease of dealing, has a significant impact on different areas, especially in smart cities. An example of that is the use of a driverless minibus service, a pressure management system to leverage water network data and lighting controls.

Smart cities distinguished by using high technologies to facilitate life for citizens [3]. The purpose of smart cities is to improve the quality of life, increase the level of development, increase economic growth and harnessing technology, especially technology that leads to efficient outcomes [4].

One of the problems we are trying to solve here is controlling the traffic congestion. Thus, we are working on building a prototype system for solving the traffic congestion issue. Throughout the literature review, the recommended solution was to design a density-based traffic signal system, for making traffic flow more efficient. 
Our aim is to facilitate and optimize traffic flow, minimize traffic congestion, and reduce the waiting time.

\subsection{Problem definition}

Traffic congestion is a serious issue in several big cities worldwide. Traffic can be controlled in the main junctions by including either an automatic traffic light control system or by traffic police. However, the conventional traffic light system is based on a static/fixed time concept dedicated to each street regardless of the diversity of traffic density. Sometimes, the most congested road has to be prioritized, in terms of a number of vehicles. Thus, we propose a developed design that incorporates density as a factor that affects the traffic light system.

\subsection{Objective}

The objective of our project is to regulate the traffic flow by means of introducing sensors at traffic lights on the main roads as a Smart Traffic Control System (STCS). Based on these sensors, the streets' density is detected, traffic monitoring, and automatic control of the traffic light to reduce traffic congestion. The sensors calculate the traffic density on a particular road and change the priority of traffic light based on the cars' numbers waiting on the same road thus reduce the waiting time.

\section{$2 \quad$ Literature Review}

Traffic Congestion is a persistent issue in several cities worldwide. Traffic lights play a vital role in traffic safety. Even though road safety is important [5] and even though we are in the 4th industrial revolution era, unfortunately, the current traffic system still has many problems since it's based on a fixed time concept dedicated to each street (side of the junction) regardless of the diversity of traffic density.

Traffic delay has many side effects on daily life. To a commuter or a traveler, congestion means wasting time, wasting opportunities, and frustration. In addition, for business providers, congestion means losing trade opportunities, delivery delays, and increasing costs [6]. These issues need to be solved by developing automated transportation management systems. Many pieces of research and studies have been conducted that provided different hypotheses and solutions. Lo and Chow explained the Dynamic Intersection Signal Control Optimization (DISCO) system which is a platform for modeling dynamic traffic in Hong Kong [7]. Ref. [8] provided a traffic light control system based on Wireless Sensor Networks (WSN) that has the ability to revolutionize control technology and traffic surveillance due to its potential for large scale deployment and low cost. Ref. [9] designed an HMS Algorithm based on the Modified Round Robin algorithm. HMS reveals the enhancement of traffic light services in Iraq where it reduced waiting time and ensure the maximum use of roads. Ref. [7] explained another solution that used multiple IR sensors that had been installed on roads for density measurement. The increases in the number of IR sensors 
have improved the accuracy of density measurement. Moreover, it was explained that the traffic lights that are connected with the output port of the IR sensors and Arduino processor were linked with an input port of the Arduino processor through the feedback path. A system such as this acts as an interfacing device which supports the Lab VIEW software and better decision making on road base upon traffic density. Finally, the traffic light control system using Arduino is a system designed to make traffic lights more flexible, so that it can measure the proportion of traffic density, a central device where all the traffic lights are linked, it can be controlled remotely and it changes its scheduling without the need to change it manually. A Comparison between some traffic control systems is shown in Table 1.

Table 1. Comparison between systems.

\begin{tabular}{|l|l|l|c|}
\hline \multicolumn{1}{|c|}{ Name } & \multicolumn{1}{|c|}{ Objective } & \multicolumn{1}{c|}{ Tools/technique } & Reference \\
\hline $\begin{array}{l}\text { Intelligent Traffic Light } \\
\text { Flow Control System }\end{array}$ & $\begin{array}{l}\text { Handle the case of control- } \\
\text { ling traffic over multiple } \\
\text { intersections. }\end{array}$ & $\begin{array}{l}\text { WSN } \\
\text { Traffic system communication } \\
\text { algorithm (TSCA) } \\
\text { Traffic signals time manipulation } \\
\text { algorithm (TSTMA). }\end{array}$ & [8] \\
\hline $\begin{array}{l}\text { IoT Based Traffic Signal- } \\
\text { ing System }\end{array}$ & $\begin{array}{l}\text { Analyze the traffic conges- } \\
\text { tion as Heavy traffic and } \\
\text { Normal Traffic with date and } \\
\text { time based on the data that } \\
\text { Ras been sent wirelessly to } \\
\text { Raspberry Pi3 and updated } \\
\text { on Cloud webpage which can } \\
\text { be used for further planning } \\
\text { and analysis by the Traffic } \\
\text { department. }\end{array}$ & $\begin{array}{l}\text { Ultrasonic Sensor } \\
\text { ESP8266 Wi-Fi Module } \\
\text { Arduino Microcontroller (Arduino } \\
\text { Uno can be programmed with } \\
\text { Arduino Software IDE). } \\
\text { Raspberry Pi3. } \\
\text { Cloud webpage } \\
\text { Cloud server. }\end{array}$ & {$[10]$} \\
\hline $\begin{array}{l}\text { Smart Autonomous } \\
\text { Traffic Light Switching } \\
\text { by Traffic Density Meas- } \\
\text { urement through Sensors }\end{array}$ & $\begin{array}{l}\text { Enable dynamic switching of } \\
\text { traffic light and timing based } \\
\text { on traffic density. } \\
\text { Reduces the Average Trip } \\
\text { Waiting Time (ATWT). }\end{array}$ & $\begin{array}{l}\text { Infrared sensor } \\
\text { Low power Energy Microcontroller } \\
\text { Comparator } \\
\text { Radio Communication module. }\end{array}$ & {$[11]$} \\
\hline
\end{tabular}

Next, the methodology of conducting this study will be explained.

\section{$3 \quad$ Materials and Methods}

Four stages have been done to learn how to solve the problem of controlling the traffic based on the density of the roads.

Firstly: before we create the system, we distributed a questionnaire to investigate some important issues such as the community's acceptance of the idea. The questionnaire was in Arabic, for all ages and both genders in Jeddah, Saudi Arabia. It was an online survey using Google forms, it contained 11 questions and we received 331 responses. 


\subsection{Analysis of the collected data}

Significantly, about $80 \%$ of the responders agreed that the current traffic signal system needs to be developed and about $94 \%$ of responders support the need to have a traffic system that changes the time based on traffic density (see Figure 1). We found that the community accepts the smart traffic control system and the community believes that it is a good idea and it would be beneficial to them.

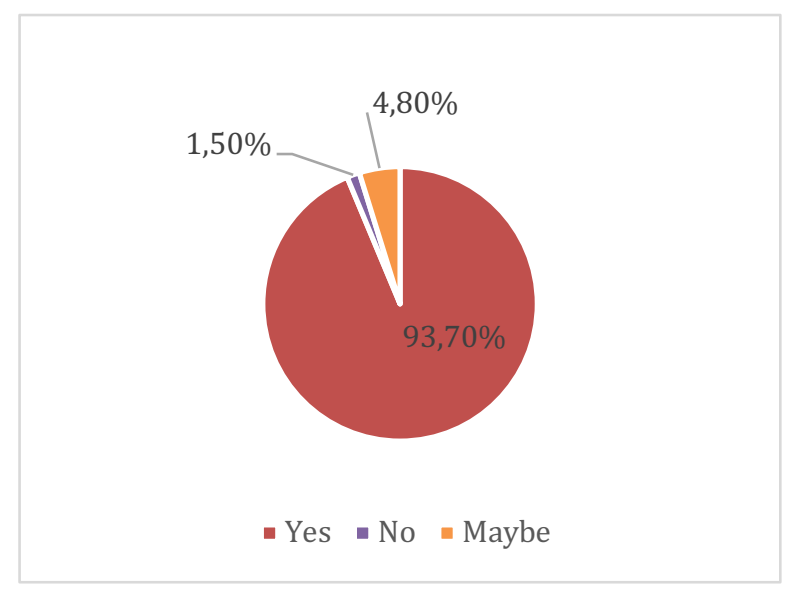

Fig. 1. The level of Supporting a Smart Traffic Control System

Secondly: We used the Proteus simulator to check the concept in software before the hardware implementation (see Figure 2).

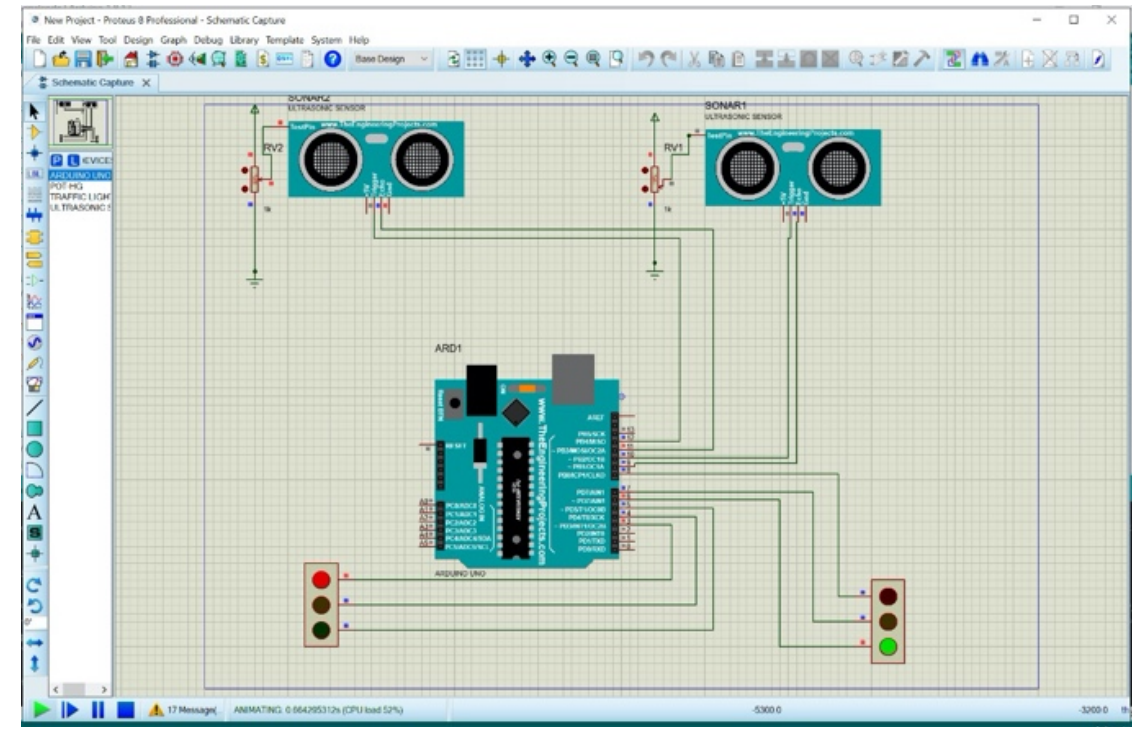

Fig. 2. STC system on the Proteus simulator 
Implementing the concepts in the simulator by using a combination of an ultrasonic sensor, open source Arduino IDE and MATLAB to develop the real system of traffic light control. Keeping in mind that the sensors are used to detect the traffic density by calculating the number of cars in each road and then analyzing that data. The calculations are done by dividing the time to serve the four roads based on the needs and this concept also known as the inclusion management strategy in the administration field. In the simulation of the STCS we employed Arduino Uno and an ultrasonic sensor. The ultrasonic sensor and the signals are connected to the Arduino microcontroller to control the traffic lights. The Traffic light changes to RED or GREEN based on traffic density using the changing resistance RV1 and RV2 which is what we used for the simulation to pretend that there is traffic or not because we could not use cars for density test in the simulation. If there is traffic at a signal, the signal will turn GREEN and vice versa it turns RED. We worked in the simulation to make sure everything is feasible to be applied with real parts (hardware) with confidence.

Thirdly: Building a prototype which has been done since this is a vital facet of the product design and development process. Building prototypes helped to reduce the design risk of wasting cost and time of a full production [12]. System design and implementation is the phase of developing an executable software system in the process of software engineering process [13]. During the design development phase, all the decisions that are related to the design, equipment's and functional requirements to the used shapes, objects and the basic colors were documented[14]. We found at this phase that the act of building prototypes encourages reflection in the design aspect, as recognized by designers from many disciplines, is an important aspect of the design process [15]. The product regularly goes through various versions of prototypes before the design is completed. See Fig. 3 of the low fidelity prototype.

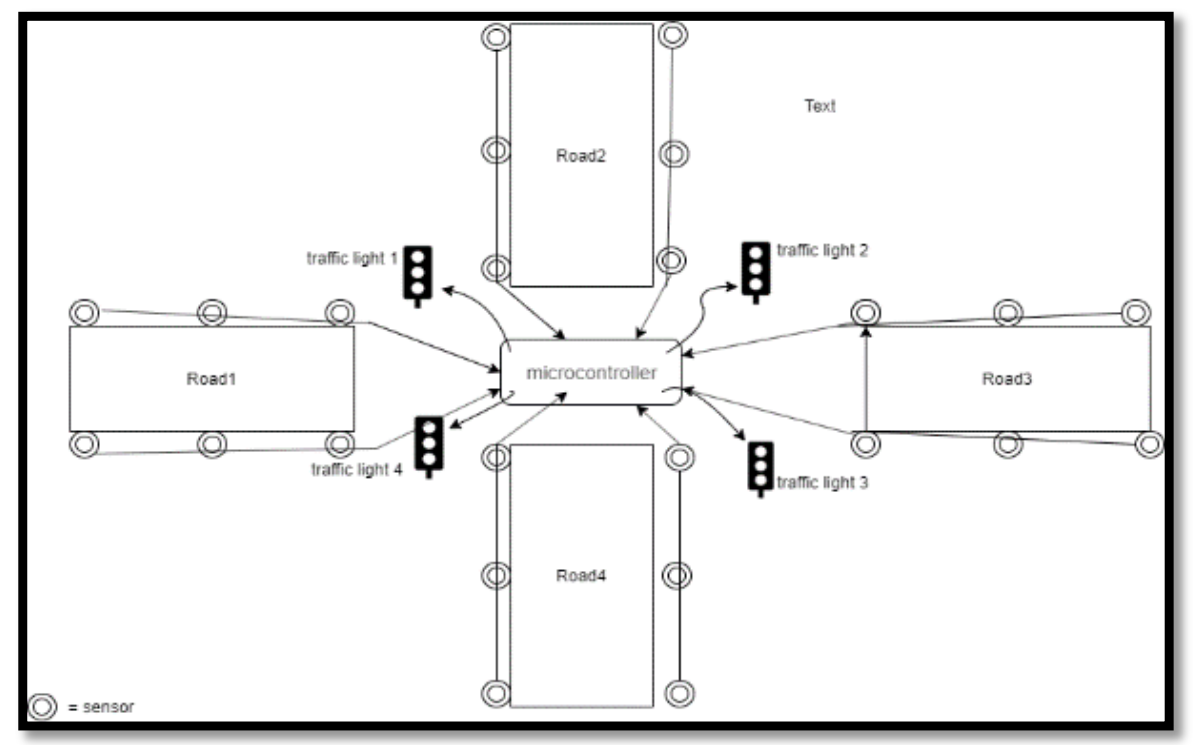

Fig. 3. Low Fidelity Prototype 
Fourthly: Building the STCS model by Arduino tools and Arduino Software IDE. The following peace of code is an example of the code in the Arduino Software IDE.

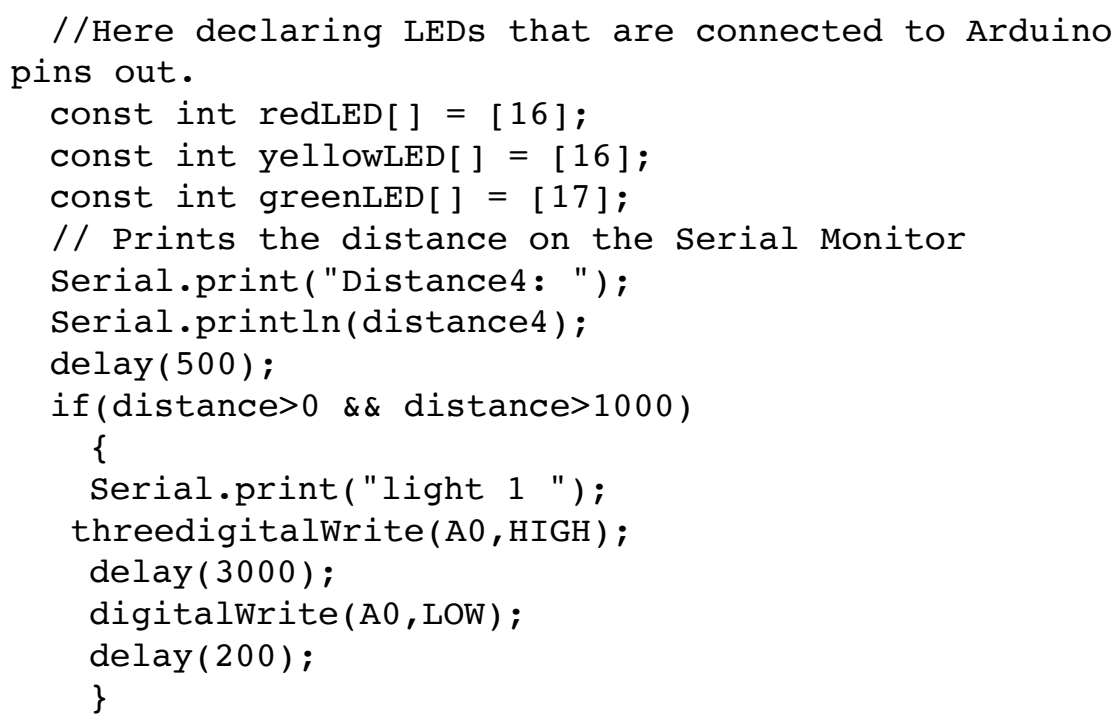

The hardware implementation has been done by using Ultrasonic sensors (see figure 4) and Arduino Uno Microcontroller (see Figure 5). Furthermore, the Arduino has been chosen for the following reasons:

- Arduino boards are relatively inexpensive.

- The Arduino Software (IDE) can be run on different operating systems such as Macintosh, Linux and Windows.

- $\mathrm{C}++$ programming language can be used [18].

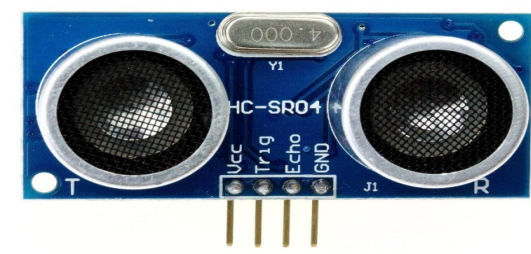

Fig. 4. The Ultrasonic Sensor

An ultrasonic sensor had been used because it reflected sound waves and then measured the distance to an object by measuring the time taken by the sound to reflect back from the object. Ultrasonic Sensor has 4 pins. Ultrasonic distance sensor module is an electrical device that measures the distance of an object by emitting ultrasonic sound waves and converts the reflected sound into an electrical signal [19].

Two sensors have been placed next to each traffic light to detect nearby cars. 


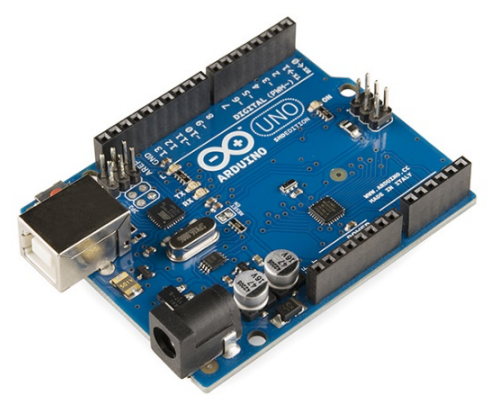

Fig. 5. Arduino Uno Microcontroller.

Arduino Uno is a microcontroller board which has 14 digital input/output pins and can be programmed with Arduino Software IDE [6]. Figures 6 and 7 show the connection between Ultrasonic sensors, traffic lights, the breadboard (the white one) and Arduino Board via wires.
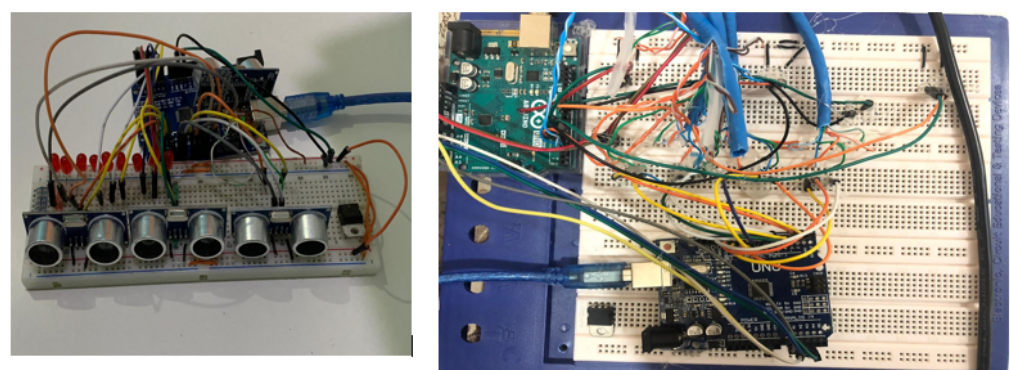

Fig. 6. Hardware connections.

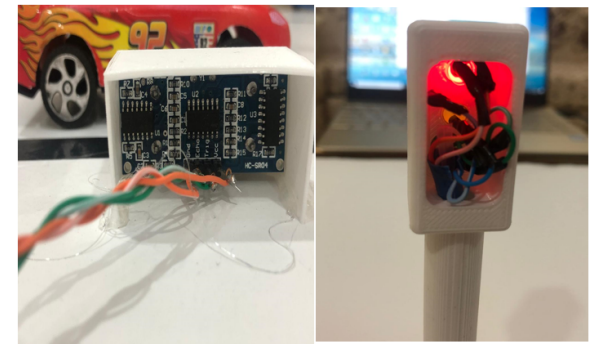

Fig. 7. The wired connecting between traffic light and ultrasonic sensors.

\section{$4 \quad$ Results and Discussion}

As mentioned, that STCS is based on the traffic density on the road, where the vehicles that existed on the road are counted by the sensor which is placed on each side of the road and automatically controls the traffic lights according to the traffic density. 
In this system, two pairs of sensors are placed on each side of road and four traffic lights. Arduino Microcontroller controls the ultrasonic and counts the number of vehicles passing on the road where the signals are changed when the sensor assumes that there is traffic congestion on the road. There are 3 cases in this system as follows:

1. If there are no vehicles present on the road then light is (Red), until vehicles are arrived (see Figure 8).

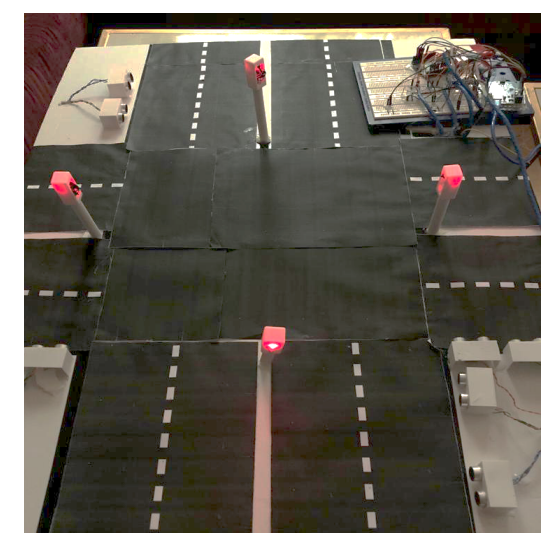

Fig. 8. The practical STCS first case.

2. If there is varying number of the traffic density at signals, the system changes the priority of traffic light GREEN for the road that have the highest density (see Figure 9).

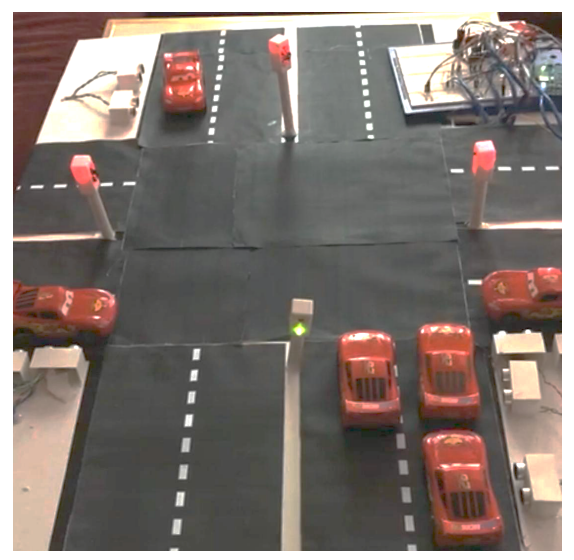

Fig. 9. The practical STCS second case.

3. In the case of all roads having an equal density, its actives the status of the sequential arrangement between the roads and the system will work normally by controlling the signals one by one. 


\subsection{Testing}

In order to run the whole system, we needed:

- Led traffic light module: That showed the lights red, yellow and green

- Arduino Microcontroller: Physical programmable circuit board that contains the code from the Arduino IDE software [20]

- Wires male-female: A group of electrical wires in a cable, with a connector or pin at each end

- Breadboard: A construction tool base for the prototyping of electronics used to design and test the circuit

- Arduino Adaptor: Used to power the Arduino board via the plug from a wall outlet.

- Laptop

Then, we applied functional testing for evaluating the system and verifying each function of the system, to check if it conforms to the required specification, the tests include: unit testing, integration testing, compatibility testing and system testing. Unit Testing is done during the development (coding phase) of an application by the developers [21]. The unit testing was applied to all cases as described. Integration testing: a complete system is tested to guarantee that the requirements of the software have been met [22]. During the system testing we were focusing on validating the proper work complete system after the integration. four cases have been coved as follows:

- By default, all traffic lights are in (red) until vehicles are present

- In the case of a denser road, it has the priority to turn the traffic light into (green)

- In the case of all roads having an equal density, it activates the status of the sequential arrangement between the roads

- In the case of two roads with the same density, the priority is to turn the traffic light green to the road who started congesting first

\section{Conclusion and Future Work}

With the rapid increase in motorization industry, urbanization, population growth, and changes in population density, the problem of traffic congestion has increased worldwide. Therefore, we built an STCS with the aim of regulating traffic flow and reducing traffic congestion. This will lead to providing a good service for the community. We wish to succeed in the future by applying this smart system nationally and internationally.

\subsection{Difficulties and limitation}

During the work on the project, COVID-19 disturbed the world and we could not buy more tools. The process of learning how to connect the Arduino parts was not easily managed online since we were as a team that needs to meet face to face, in the 
quarantine period. Furthermore, we discovered that the Ultrasonic Sensor has a limited detection range so it is will work only for the prototype.

\section{$5.2 \quad$ Future work}

We recommend using Mega Arduino instead of Uno Arduino because of its better capacity. Future research can link this system with google maps. Furthermore, we recommend transferring data from the microcontroller and sensors to an application so users can access the data collected by the system and make some visualizations and predictions. Further research can add more sophisticated improvements on the current applied system.

\section{Acknowledgement}

We would like to thank Engineer Mohammed Salem Almalki for all his efforts with us.

\section{$7 \quad$ References}

[1] S. Seiler, R. Sell, and D. Ptasik, "Embedded System and Robotic Education in a Blended Learning Environment Utilizing Remote and Virtual Labs in the Cloud, Accompanied by â?? Robotic HomeLab Kitâ??," International Journal of Emerging Technologies in Learning (iJET), vol. 7, no. 4, pp. 26-33, 2012. https://doi.org/10.3991/ijet.v7i4.2245

[2] S. A. Garba, Y. Byabazaire, and A. H. Busthami, "Toward the Use of 21 st Century Teaching-Learning Approaches: The Trend of Development in Malaysian Schools within the Context of Asia Pacific," International Journal of Emerging Technologies in Learning, vol. 10, no. 4, 2015. https://doi.org/10.3991/ijet.v10i4.4717

[3] R. P. Dameri, "Searching for smart city definition: a comprehensive proposal," International Journal of computers \& technology, vol. 11, no. 5, pp. 2544-2551, 2013. https://doi.org/10.24297/ijct.v11i5.1142

[4] "What is Smart City." http://smartcities.gov.in/content/innerpage/what-is-smart-city.php (accessed 20/09/2019.

[5] T. A. Alhmiedat, F. Omar, A. A. Taleb, and A. Alsswey, "Road safety and energy saving proposed system: A ZigBee WSN approach," International Journal of Online and Biomedical Engineering (iJOE), vol. 11, no. 2, pp. 55-59, 2015. https://doi.org/10.3991/ij oe.v11i2.4430

[6] E. F. B. Poyen, A. K. Bhakta, B. D. Manohar, I. Ali, A. ArghyaSantra, and A. Rao, "Density based traffic control," International Journal of Advanced Engineering, Management and Science, vol. 2, no. 8, p. 239611, 2016.

[7] G. Kapapula and P. Mittal, "A Novel Approach for Dynamic Road Traffic Management System (DRTMS) with Lab VIEW and Arduino," International Research Journal of Engineering and Technology (IRJET), vol. 2, no. 05, 2015.

[8] K. M. Yousef, M. N. Al-Karaki, and A. M. Shatnawi, "Intelligent traffic light flow control system using wireless sensors networks," J. Inf. Sci. Eng., vol. 26, no. 3, pp. 753-768, 2010 . 
[9] H. K. Hamarashid, M. H. R. Saeed, and S. Saeed, "Designing a Smart Traffic Light Algorithm (HMS) Based on Modified Round Robin Algorithm," Kurdistan Journal of Applied Research, vol. 2, no. 1, pp. 27-30, 2017. https://doi.org/10.24017/science.2017.1.8

[10] A. PV, V. Mani, and S. Sankaranarayanan, "IoT Based Traffic Signalling System," International Journal of Applied Engineering Research, vol. 12, no. 19, pp. 8264-8269, 2017.

[11] Y. Jagadeesh, G. M. Suba, S. Karthik, and K. Yokesh, "Smart autonomous traffic light switching by traffic density measurement through sensors," in 2015 International Conference on Computers, Communications, and Systems (ICCCS), 2015: IEEE, pp. 123-126. https://doi.org/10.1109/ccoms.2015.7562885

[12] M. G. Helander, Handbook of human-computer interaction. Elsevier, 2014.

[13] I. Sommerville, ",Software Engineering 10 “," Harlow: Pearson Education Limited, 2016. [Online]. Available: https://dinus.ac.id/repository/docs/ajar/Sommerville-SoftwareEngineering-10ed.pdf

[14] "Construction Services." University of California. https://www.ucop.edu/constructionservices/facilities-manual/volume-3/vol-3-chapter-1.html (accessed 21/11/2019.

[15] J. Preece, H. Sharp, and Y. Rogers, Interaction design: beyond human-computer interaction. John Wiley \& Sons, 2015.

[16] "Air pollution causes 800000 extra deaths a year in Europe," (in English), Br. J. Hosp. Med., News Item vol. 80, no. 4, pp. 189-189, Apr 2019. [Online]. Available: <Go to ISI $>$ ://WOS:000463570900018.

[17] S. S. Basu, S. Tripathy, and A. R. Chowdhury, "Design challenges and security issues in the Internet of Things," in 2015 IEEE Region 10 Symposium, 2015: IEEE, pp. 90-93. https ://doi.org/10.1109/tensymp.2015.25

[18] Arduino. https://www.arduino.cc (accessed.

[19] D. Jost. "FierceElectronics." https:/www.fierceelectronics.com/sensors/what-ultrasonicsensor (accessed 26/03/2020.

[20] LabCenter. "PCB Design and Circuit Simulator Software " https://www.labcenter.com (accessed).

[21] Rajkumar. "What Is Software Testing Definition, Types, Methods, Approaches." https://www.softwaretestingmaterial.com/software-testing/ (accessed).

[22] I. Sommerville, Software Engineering GE. Pearson Australia Pty Limited, 2016.

\section{Authors}

Mashael Khayat has been the Department of Computer and Network Engineering supervisor and an assistant professor in the IST Department at the College of Computer Science and Engineering at Jeddah University since 2017. Dr. Khayyat was granted a Ph.D. degree in Computer Science and Statistics from Trinity College Dublin (TCD), Dublin, Ireland. Dr. Khayyat has received international and distinguished research grants from the University of Jeddah. Her research interests in Engineering, Visualization, Augmented Reality, Technology Management, and Open Government data. (email: mkhyyat@uj.edu.sa)

Omar Abouola is an Assistant Professor at the Information Systems and Technology Department, College of Computer Science and Engineering (CCSE), University of Jeddah. He obtained his bachelor degree of science in Computer Science from KAU back in 2001. In 2009, He earned his master degree in Information Science from University of Indiana, Bloomington, USA. His master thesis was related 
to the technology of banking. Dr. Aboulola received his Ph.D. in Information Systems and Technology, from Claremont Graduate University (CGU), USA, 2018. His PhD dissertation aimed to design an innovative assistive technology to Help retail companies to predict optimum locations for their businesses. (email: oaboulola@uj.edu.sa)

Nahla aljojo obtained her $\mathrm{PhD}$ in Computing at Portsmouth University. She was Associate Professor at Faculty of Computing and Information Technology Information System Department - King AbdulAziz University, Jeddah, Saudi Arabia. She is working currently as Associate Professor at College of Computer science and Engineering, Information system and Information Technology Department, University of Jeddah, Jeddah, Saudi Arabia. Her research interests include adaptivity in web-based Educational Systems, E-business, leadership's studies, information security and Data Integrity, E-Learning, Education, and Machine Learning (e-mail: nmaljojo@uj.edu.sa)

Basma Alharbi received a B.Sc. degree in Computer Science from Effat University, Jeddah, Saudi Arabia in 2008, and a M.Sc. degree in Computer Science from Durham University, Durham, United Kingdom in 2009. She received her Ph.D. degree in Computer Science from King Abdullah University of Science and Technology (KAUST), Thuwal, Saudi Arabia in 2017. Dr. Alharbi is currently an assistant professor at the Computer Science and AI department, in the College of Computer Science and Engineering, at the University of Jeddah, Jeddah, Saudi Arabia. Her research interests include machine learning and its applications, representation learning and knowledge discovery (e-mail: bmalharbi@uj.edu.sa).

Nada Almalki graduated in 2020 with a Bachelor of Information systems and Technology, from the College of Computer Science and Engineering at the University of Jeddah, Jeddah, Saudi Arabia (e-mail: Salem.nada@hotmail.com).

Maysoon Al-zahrani graduated in 2020 with a Bachelor of Information systems and Technology, from the College of Computer Science and Engineering at the University of Jeddah, Jeddah, Saudi Arabia (e-mail: mailto:mmamjartist@gmail.com).

Tasneem Al-ghamdi graduated in 2020 with a Bachelor of Information systems and Technology, from the College of Computer Science and Engineering at the University of Jeddah, Jeddah, Saudi Arabia (e-mail: T.ali4@yahoo.com).

Lama Al-qarni graduated in 2020 with a Bachelor of Information systems and Technology, from the College of Computer Science and Engineering at the University of Jeddah, Jeddah, Saudi Arabia.(email: Lama-algarni@hotmail.com).

Article submitted 2020-07-06. Resubmitted 2020-08-6. Final acceptance 2020-08-07. Final version published as submitted by the authors. 